\title{
从『黄帝内经』肾之功能探析『金贵要略』肾气丸气化作用的体现
}

北京中医药大学 临床基础医学院 ${ }^{1}$

朴恩希 $^{1} \cdot$ 謝茥 $^{1} \cdot$ 賈春華 $^{1^{*}}$

\section{The Essential Prescriptions of the Golden Chamber (金贵要略) use of Shen Qi Pill(肾气丸)'s for qi's transformation(气化), truly embodies the analysis found in the Yellow Emperor internal classic(黄帝内经) describing the kidney functions.}

\author{
Park Eun $\mathrm{Hee}^{1} \cdot$ Xie Jing ${ }^{1} \cdot$ Jia Chunhua $^{{ }^{*}}$ \\ ${ }^{1}$ Preclinical Department, Beijing University of Chinese Medicine, Beijing, China
}

Objective : This article is based on a formula taken from Essential Prescriptions of the Golden Chamber(金贵要略). Shen Qi Pill(肾气丸) is generally used for such deficiency cases as: consumptive diseases, xiaoke(消渴) (waisting, thirst), beriberi, urinary problems during pregnancy, phlegm and so forth, and its main purpose is to treat Kidney Qi depletion, Qi transformation disorders, without obvious hot/cold appearance patterns.

Method : Mainly through the literature study of related treatise on Inner Canon of the Yellow Emperor's internal classic(黄帝内经) and The Essential Prescriptions of the Golden Chamber.

Result : According to the Yellow Emperor's internal classic, the Kidney has three main functions, storing essence, controlling the waters and holding Qi. Shen Qi Pill's(肾气丸) source formula is intended to supplement even though its constituent herbs aren't the warming type. To reinforce the Qi's transformation ability is considered to be a main function of the kidney organ, and in clinic, diagnosed kidney related problems and its treatment process are mainly associated with warming to help the Qi transforming.

Conclusion : Thus recovering the kidneys Qi's transformation function is part of the process to eliminate diseases. Just cause the Kidney is deficient we shouldn't think immediately of using warming supplement herbs.

Key words : Yellow Emperor's internal classic(黄帝内经), Essential Prescriptions of the Golden Chamber(金贵要略), Shen Qi Pill(肾气丸), Qi's transformation(气化). 


\section{I . 绪 论}

肾气丸最早见于医圣张仲景所著的『金匮、要略』中前 后共出现 4 次, 分别用于治疗虚劳腰痛, 消渴, 转胞, 痰 饮．后世医家尤怡在『金贵翼』「脚气少腹不仁」中又增加 了以肾气丸治疗脚气的记载. 上述 5 条均为肾气丸在临 床常见疾病中的应用, 即通过调整气化功能来治疗疾病. 有爸肾脏气化功能的理论体系阐释始自『黄帝内经』, 张 仲景的肾气丸突出体现了肾脏气化的重要性, 其临床应 用正是气化功能障碍病理表现的归纳. 实际上，『金贵 要略』是『黄帝内经』爸于肾脏气化功能理论的传承和发 扬，后者是前者的基础，前者是后者的延伸，两者是一 脉相承的䏌系.

\section{II. 本 论 \\ 1.『黄帝内经』对肾之功能的论述}

\section{1 肾主藏精}

在『金贵.要略』「血瘰虚劳病脉证」15中载：“虚劳腰 痛, 少腹拘急, 小便不利者, 八味肾气丸主之.” 肾主生 殖, 肾藏精, 肾气虚衰或肾精不足则可引起腰痛。『素 问』脉要精微论」载“腰者, 肾之府, 转摇不能, 肾将急 矣”, 唐代王冰注云: “两肾在于腰内, 故腰为肾之外腑 ”.1）故“虚劳腰痛” 者多认为因在肾虚. 如在『圣济总录 』腰痛门」有: “虚劳腰痛者, 劳伤于肾也.”在『素问』 上古天真论」中：“……七八,肝气衰, 筋不能动, 天癸 竭, 精少, 肾脏衰, 形体皆极.”2) 说明了肾气的盛衰与 人形体, 发育的密切䏌系。又灵枢』本脏」有: “经脉 者, 所以行气血而营阴阳，濡筋骨而利朵节.”说明了气 血可以濡养筋骨, 通利䏌节, 经脉是其通行的道路, 气 血功能的实现有赖于人体阴阳的平衡和阴阳之气的营 养. 『灵枢』「调经论」云: “血气者, 喜温而恶寒, 寒则

* 교신저자 : 贾春华教授. 北京中医药大学临床基础医学院. 地址: 中国北京市北三环东路11号. 北京中医药大学基础医 学院金贯教研室82\#信箱. 邮编：100029.

E-mail : jiachunhua555@yahoo.com.cn

Tel : 86-10-6428-6994

접수일(2012년 10월 15일), 게재확정일(2012년 11월 16일).

1）马莳 撰. 黄帝内经灵枢注证发微. 北京. 人民卫生出版社. 1998. p.122.

2）马苻 撰. 黄帝内经灵枢注证发微. 北京. 人民卫生出版社. 1998. p.6.
泣而不流，温则消而去之”. 又说明了气血功能的正常 发挥依赖阳气的温养, 得温气血即可正常的运行, 发挥 濡笳骨而利爸节的功能，寒则气血㠜滞而不行. 『素问』 「至真要大论」中所述病机十九条载“诸寒收引, 皆属于 肾.”3）肾主北, 在天为寒, 在地为水, 属阴中之阴而内 藏元阳。人体内生阴寒或外感风寒所致的肢体爸节收而 不用，都均可归属于肾脏功能的失常. 因此虚劳腰痛, 少腹拘急, 小便不利，病因在于肾中真阳内微，虚寒内 生或阳虚外感寒邪所致. 如『素问』「刺法论」所述：“正 气存内，邪不可干，邪之所凑，其气必虚。” ${ }^{4}$ 肾中真阳 虚衰即可内生虚寒, 又易外感寒邪。经脉喜温而恶寒, 血气在经脉中，寒者泣涩，温者通利．若肾中元阳不足， 内生阴寒，不能正常的温煦经脉，则经脉不利，气血泣 而失其畅行, 寒主收引, 腰部筋脉缺少气血的正常涵 养，寒邪痹阻经脉，正虚邪客，内外合邪，虚实夹杂． 所以仲景以八味肾气丸补阴之虚以生气, 助阳之弱以化 水, 用补下, 治下之法治疗虚劳腰痛.

后世医家程林在『醫宗金鑑』金實要略解」释：“腰者 肾之外侯, 肾虚则腰痛; 肾与膀胱为表裡, 不得三焦之 阳气以决渎, 则小便不利而少腹拘急矣, 于是方以益肾 间之气, 气强则便溺行, 而少腹拘急亦愈矣.” 尤怡曰： “虚劳之人”损伤少阴肾气，是以腰痛，少腹拘急，小便 不利.”『金贾要略心典』中对此句的解释曰：“下焦之 分，少阴主之，少阴虽为阴脏，而中有元阳，所以温经 脏，行阴阳，司开睓者也. 虚劳之人，损伤少阴肾气，是 以腰痛，少腹拘急，小便不利. 程氏所谓肾间动气已损 者是矣，八味肾气丸. 补阴之虚，可以生气，助阳之弱， 可以化水, 乃补下治下之良剂也.”5)

\section{2 肾主水}

『金圄、要略』「中风历节病脉证」载：“治脚气上入, 少 腹不仁.”中医脚气的概念是指以腿脚麻木, 酸痛, 软 弱, 或孪急, 肿胀, 或枯萎等为主要表现的疾病. 临床 以两下肢软弱无力为特征. 主要表现为知觉麻木, 微肿 酸疼, 软弱不能行, 甚或喘急心悸等. (『中医内科学』

3）马莳 撰. 黄帝内经灵枢注证发微. 北京. 人民卫生出版社. 1998. p.613.

4）马莳 撰. 黄帝内经灵枢注证发微。北京. 人民卫生出版社. 1998. p.682.

5）尤怡 著. 金贯要略心典. 上海. 上海卫生出版社. 1956. p.57. 
教材）『黄帝内经』载：肾主骨生髓, 下肢㽷弱酸肿，与 肾脏功能失调有兊. 而肿胀属水液代谢失常范盽, 与外 感湿邪或水湿运化障碍爸系密切。『素问』上古天真论」 谓; “肾者主水, 受五脏六腑之精而藏之.”6) 肾气参与机 体水液代谢, 助膀胱气化开睓, 承担化生尿液和排泄尿 液之职, 这一功能的实现即靠肾气的蒸化作用及肾阴 和肾阳的平衡调节, 肾藏元阴元阳, 肾阴又称元阴, 肾 阳又称元阳。明·张介宾在『景岳全书』云: “五脏之阴气 非此不能滋, 五脏之阳气非此不能发。” 肾气由肾阳蒸 腾肾阴化生而来『黄帝内经』载: “气归精, 精化为 气”, 故肾精与肾气又可互相转化. 『素问』「六节脏象论 」说: “肾者主蛰, 封藏之本, 精之处也.”7) 对精气做了详 细描述, 具体来说, 精属阴, 言物质; 气属阳, 主功 能; 精气互化, 水火同宅, “火”加于 “水”化生气, 肾之 气，“一气”贯阴阳，精化气. 所以“肾气”一虚，到一定 程度, 由其演化的肾阴肾阳俱虚. “补阴之虚, 可以生 气; 助阳之弱, 可以化水”。

\section{3 肾主纳气}

在『金贾, 要略』痰饮咳嗽病脉证」日：“夫短气有微 饮, 当从小便去之, 苓桂术甘汤主之. 肾气丸亦主之” 的“微饮”是水饮轻微者, 即『金贵要略』所载“水停心下, 微者短气”之理. 『黄帝内经』中虽然没有明确记载“肾主 纳气” 的观点, 但呼吸功能与肾脏相爸的学术思想在 ${ }^{『}$ 黄帝内经』中已有体现，肾上连于肺，其脉上贯膈，入 肺中.『素问』逆调论」指出: “肾者……主卧与喘.” 『难经』四难」解释: “呼出心与肺, 吸入肝与肾”均说 明了肾脏与呼吸尤其是吸气异常的爷系十分密切. 后世 医家不断积累总结临床经验, 将与呼吸功能相爸的脏腑 总结形成较为完整的理论体系. 如『仁斋直指方论』「附 补遗·咳嗽日: “肺出气也, 肾纳气也, 肺为气之主, 肾 为气之藏.”9）林氏在『类证治裁』喘症」中载：“肺为气 之主, 肾为气之根. 肺主出气, 肾主纳气, 阴阳相交, 呼

6）马苻 撰. 黄帝内经灵枢注证发微. 北京. 人民卫生出版社. 1998. p.8.

7）马莳 撰. 黄帝内经灵枢注证发微. 北京. 人民卫生出版 社.1998. p.87.

8）马莳撰. 黄帝内经灵枢注证发微。北京. 人民卫生出版 社.1998. p.232.

9）杨土瀛 著. 仁斋直指方论. 福建. 福建科学技术出版社. 1989. p.276.
吸乃和．若出纳升降失常，斯喘作矣.”10）此条微饮之 病, 外证不甚明显, 仅见短气, 似属轻微. 然饮邪虽轻 微, 水饮内停, 妨碍气机升降则短气, 阳气不化可见 小便不利, 且需要分辨其本在脾在肾之不同。“当从小 便去之”即应以化气利小便之法，使气化水行，饮有去 路, 则“短气”症状可除. 但水饮的形成, 原因有中阳不 运和下焦阳虚两端, 故应遵从辨证论治的原则, 分别遣 方用药. 前者病位在脾, 兼证可见心下逆满, 起即头眩 等; 后者病位在肾, 争证见畏寒足冷, 小腹拘急不仁 等. 故前者应以苓桂术甘汤健脾利水; 后者则以肾气丸 温肾化水。两方皆从『金贵要略』载“病痰饮者，当以温 药和之”的治疗原则. 张仲景将补肾法用于呼吸异常的 治疗，以肾气丸理肾气，温肾阳，化饮利水，有补有泻， 有热有凉, 开合有度, 饮去短气自和.

今临床实践也表明，肾气丸具有补肾，化痰，活血， 止咳的功能, 以补肾纳气为主，是治疗内伤久咳之良 药.11）金贵要略心典』对词条的解释为: “气为饮抑则 短，欲引其气，必蠋其饮，饮水类也. 治水必自小便去 之, 苓桂术甘益土气以行水, 肾气丸养阳气以化水, 虽所主不同，而利小便则一也.”12) 在『金贵要略』消 渴小便利淋病脉证」日：“男子消渴，小便反多，以饮 一斗，小便一斗，肾气丸主之.”『医宗金鉴』将消渴分 为三类: “饮水多而小便少者. 水消于上, 故名上消也. 食谷多而大便坚者，食消于中，故名中消也. 饮水多而 小便反多者, 水消于下, 故名下消也. 上中二消属热, 惟下消寒热夈之, 以肾为水火之脏也. 饮一溲一, 其中 无热耗可知矣.”13）『素问』逆调论」：“肾者水脏，主 津液.”14）『难经』「四十四难」:“肾主五液”明确说明了 肾与水液代谢密切相爸. 肾主水, 合三焦, 膀脂二腑主 津液, 与肺, 脾二脏共司体内水液代谢和调节, 是人体 水液代谢中最重要脏器. 一方面是由于肾为水脏, 是胃 之爸，司二便，开䛎于二阴，肾气化则二阴通，肾气

10）林佩琴 编著. 类证治裁. 上海. 上海科学技术出版社. 1959. p.113.

11）晋玉梅. 金贵肾气丸治疗咳嗽的体会，河南中医药学刊。 1997. 12 (4) . pp.39-40.

12）尤怡 著. 金贵要略心典．上海．上海卫生出版社. 1956. p.33.

13）尤怡 著. 医宗金鉴·杂病心法要决白话解. 北京. 人民卫生出 版社. 2004. p.165.

14）马莳 撰. 黄帝内经. 北京. 人民卫生出版社. 1998. p.231. 
不化则二阴闭; 另一方面是肾的阳气为一身阳气之 根, 脾的运化, 肺的宣降, 三焦的通调, 膀胱的开 合，无不依赖肾中的阳气的作用，才能发挥正常功能， 所以肾在调节人体水液代谢方面起主导作用. 小便反 多, 排除了大热耗津的口渴, 其小便必不多所以用 “反” 字说明此处消渴是肾虚阳气衰微, 既不能蒸腾津 液以上润, 又不能化气以摄水，水尽下趋，因而“以饮 一斗, 小便一斗”, 即消渴病中之下消证候. 仲景以肾 气丸补肾之虚, 温养其阳, 以恢复蒸津化气之功, 则 消渴自除.

在『金贾要略』「妇人杂病脉证」中载：“问日：妇人病 饮食如故，烦热不得卧，而反倚息者，何也？师日： 此名转胞, 不得浔也, 以胞系了戻, 故致此病. 但利小 便则愈, 宜肾气丸主之.” 转胞之“胞”同“脬”, 即膀脱. 转胞指小溲淋励, 急迫频数或点滴不通为症状的疾病. 胞系了戻, 指膀胱之系缭绕不顺。( 『金损.要略』第五版 教材）15）『素问』「灵兰秘典论」载：“肾者，作强之 官, 技巧出焉.” 肾与膀胱经脉相连, 互为表里, 肾司膀 脱开合. 妇人脐下急痛, 小便不通, 病因在肾气不举, 膀脱气化不利所致, 故可见 “少腹胀满而不得溺” 等萧 证, 病在下焦, 中焦无病, 故饮食如故. 由于小便不 通, 浊气上逆, 故烦热不得卧, 只能倚靠着呼吸. 用肾 气丸振奋肾阳, 蒸化水气, 小便通利, 即肾阳充则气 化行之理，如此其病自愈. 正如『金贵要略心典』中所 释：“治以肾气者, 下焦之气肾主之, 肾气得理, 庶缭 者顺，戻者平，而闭乃通耳.”16)

古代医家应用肾气丸时, 病种以水肿, 痰饮, 消渴居 前3位, 现代医家应用肾气丸时, 以症闭, 水肿, 消渴居 前3位. 以上各病证病机均为肾气不充, 膀胱气化不利 致水液代谢失调. 对比『景岳全书』中的右归丸, 其中补 阳药24两, 补阴药 12 两. 另有附子, 肉桂4两温肾散寒, 可见右归丸才是温补肾阳方. 古代医家在应用右归丸 时, 病种以不孕不育, 虚劳, 腰痛居前3位, 现代医家应 用右归丸时, 以不孕不育, 虚劳, 泄泻居前3位。病机均 为肾阳虚衰，肾精不足.17）由此可见，金賈肾气丸立方

15）尤怡 著. 金贵要略心典，上海．上海卫生出版社。 1956. pp.70-71.

16）尤怡 著．金庑要略心典，上海．上海卫生出版社． 1956. pp.70-71.

17）管华全, 樊巧玲, 张永文. 肾气丸与右归丸主治疾病比较. 浙
之义在于恢复肾脏气化功能，而非温补肾阳．

\section{2. 肾气丸在『金匮要略』中的运用}

张仲景在『金贾要略』中运用肾气丸治疗各种杂病, 从上述条文中可以看有, 有虚劳腰痛, 消渴, 脚气, 转 胞, 痰饮. 病机皆为肾气亏虚, 气化开合失司所致而无 明显寒热征象的病证，反应了肾脏不同的生理功能.

1, 「血痹虚劳病脉证」 15 ：“虚劳腰痛，少腹拘急，小 便不利者，八味肾气丸主之.” 18)

2 , 痰饮咳嗽病脉证」 17 : “夫短气有微饮，当从小便 去之，苓桂术甘汤主之.|肾气丸亦主之”19)

3，「消渴小便利淋病脉证」3：“男子消渴，小便反 多, 以饮一斗, 小便一斗, 肾气丸主之.” 20)

4, 妇人杂病脉证」19：“问曰：妇人病饮食如故，烦 热不得卧，而反倚息者，何也？师曰：此名转 胞, 不得溺也, 以胞系了戻, 故致此病。但利小 便则㸝，宜肾气丸主之.”21)

5 , 『金圆翼』「脚气少腹不仁」：“治脚气上入，少腹不 仁.”22)

上述五条中三条言小便不利(转胞即妇人小便不 利), 一条言小便反多, 一条言脚气(下肢水肿), 皆属 水液代谢失常. 其中, 膀脱是直接控制小便正常排出的 器官，如『素问』「灵兰秘典论」所载：“膀脱者，州都之 官，津液藏焉，气化则能出矣.” 膀脱气化功能正常是 小便通畅排出的前提，而膀胱的气化功能的正常有赖于 肾和三焦气化作用的协调。“肾者，作强之官，伎巧出 焉. 三焦者，决渎之官，水道出焉.” 肾为水脏，主津液， 为水之下源, 是机体水液代谢的重要脏器; 若肾阳虚, 气化失司则水气内停，小便不利. 此外, 膀胱的气化还 赖于脾的运化作用, 肺的宣发肃降, 通调水道功能. 如 『素问』经脉别论」云：“饮入于胃, 游溢精气, 上输于

江中医药大学学报. 2010. 34(1). pp.81-82.

18）尤怡 著．金宽要略心典．上海．上海卫生出版社． 1956 。 p.103.

19）尤怡 著．金贵要略心典，上海．上海卫生出版社．1956 p.194.

20）尤怡 著．金匮要略心典．上海．上海卫生出版社．1956 p.226.

21）尤怡 著．金贾要略心典，上海．上海卫生出版社． 1956 pp.393-394.

22）尤怡著. 金㡶翼. 中医古籍出版社. 北京. 2003. p179. 
脾, 脾气散精, 上归于肺, 通调水道, 下输膀胱”, 若肾 气不充, 膀脱的气化失常, 致睓而不开, 水液聚于下焦, 取肾气丸, 化气利水之功, 致开而不萳, 饮一溲一, 则 取其化气摄水之功. 所以，肾气丸的功效在于充肾气而 和阴阳.23)

由于肾阴, 肾阳皆根于肾中精气, 两者相互依存, 相 互为用, 故方中重用地黄滋阴补肾为君药; 臣以山荣 英, 山药补肝脾而益精血; 加以附子, 桂枝之辛热, 助 命门以温阳化气. 又配泽泻, 获苓利水湿泄浊, 丹皮清 泄肝火, 三药于补中寓泻, 使邪去则补乃得力, 并防滋 阴药之㖑滞. 诸药合用, 温而不燥, 滋而不淢, 助阳之 弱以化水, 滋阴之虚以生气, 使肾阳振奋, 气化复常. 至唐代孙思激『备急千金要方』将方中的桂枝改为肉桂, 桂附用量各增至2两, 增加了温补药的用量, 使全方药 性偏温，用于肾阳亏虚所致诸证．今临床医生或受此影 响, 误认为肾气丸功在温阳填精, 属补益剂, 与仲景金 實肾气丸原方义在恢复肾脏气化功能不符, 实应正本清 源, 将金賈肾气丸与后世医家加减化裁之肾气丸加以区 分, 体会仲景重视肾脏气化而非温补的临床意义.

张仲景在『金圆要略』中运用肾气丸治疗各种杂病, 从上述条文中可以看有, 有虚劳腰痛, 消渴, 脚气, 转 胞, 痰饮. 病机皆为肾气亏虚, 气化开合失司所致而无 明显寒热征象的病证, 反应了肾脏不同的生理功能.

\section{3. 从肾之功能“气化”探析『金质要略』肾气丸}

\section{1. 气化功能是『黄帝内经』对肾之藏象的重要方面}

气是中国一种哲学思想中的概念, 其认为气是宇宙 万物之宗, 大千世界变化之源, 气化流行, 生生不息. “气化” 是人身之气的运动产生的变化, 是指精, 气, 血, 津液各自新陈代谢的生成及相互转化. 如气, 血, 精, 津液的生成都需要将饮食转化成水谷之精气, 然后再化 生成气, 血, 精, 津液等; 津液经过代谢后形成汗液和 尿液等代谢产物; 饮食经消化和吸收后, 转化为糟粕等 代谢产物, 都是气化作用的表现. 其中人体最基础的气 化就是肾的气化, 因为他脏的气化, 如膀胱的气化功能 都有赖于肾气化作用的协调. 因此仲景在治疗肾病时多 用温肾化气的治疗思路, 重视气化的复常, 从而使水液

23）李安祥。金贾肾气丸的五点思考。中医药通报. 2011，10(1). pp.7-9.
代谢恢复，小便通利，则其病自愈.

\section{2 气化功能不是『黄帝内经』对肾之藏象的所有方面}

『黄帝内经』中爷于肾的论述诸多, 除了气化功能外, 还有肾藏精, 主生长发育与生殖, 主水液, 主纳气等其 他几方面的功能.

其一，『素问』「上古天真论」云：“……七八，肝气 衰, 筋不能动, 天癸竭, 精少, 肾脏衰, 形体皆极.八 八, 则齿发去. 肾者主水, 受五脏六腑之精而藏之, 故 五脏盛乃能泻, ”24)说明了肾藏精, 主生长发育与生 殖, 肾藏精是指肾有摄纳, 栬存精气的生理功能。『素 问』上古天真论」记述了肾中精气由未盛到逐渐充盛, 由充盛到逐渐哀少继而耗竭的演变过程. 认识到随着肾 中精气的逐渐充盛, 人体出现“齿更”, “发长”等生长发 育的现象. 『素问』「六节脏象论」云; “肾者主蛰,封藏之 本, 精之处也.” $25 ＼mathrm{~ ） 肾 中 精 气 的 主 要 生 理 作 用 在 于 促 进 ~}$ 机体的生长, 发育和生殖能力. 因为肾所藏“先天之精” 是人体生长, 发育的根本, 所藏“后天之精”是维持生命 的物质基础. 人体生, 长, 壮, 老, 已过程与肾中精气 盛衰有䏌. 精, 是构成, 维持人体生命活动的基本物 质。『素问』金贵真言论」强调说:“夫精者，身之本也 .26)精有广义，狭义之分. 广义的精，泛指一切精微物 质，机体气、血、津液以及水谷精微皆属 “精”的范 畴; 狭义之精，仅指生殖之精。以及「灵枢・本神」所说 “生之来, 谓之精”, 即指先天之精而言.

其二, 『素问』「逆调论」日: “肾者水脏, 主津液”, 「 素问·水热穴论」日：“肾者，生脏也，地气上者属于肾， 而生水液也.”, “肾者, 胃之爸, 爷门不利, 故聚水而从 其类也.” 27）是指肾有主持和调节人体水液代谢的功 能. 在正常的生理情况下, 津液的代谢是通过胃纳摄 入, 脾的运化和转输, 肺的宣发和肃降, 肾的蒸腾气化, 以三焦为通道, 将津液输布全身, 经过代谢后的水液, 下注膀胱排出体外。『素问』经脉别论」云：“饮入于胃,

24）马莳 撰. 黄帝内经灵枢注证发微. 北京. 人民卫生出版社. 1998. p.6.

25）马莳 撰. 黄帝内经灵枢注证发微. 北京. 人民卫生出版社. 1998. p.87.

26）马莳 撰．黄帝内经灵枢注证发微．北京．人民卫生出版社. 1998. p.29.

27）马苻 撰. 黄帝内经灵枢注证发微. 北京. 人民卫生出版社. 1998. p.376. 
游溢精气, 上输于脾, 脾气散精, 上归于肺, 通调水道, 下输膀脱”, 28)

其三，『素问』逆调论」指出：“肾者……主卧与喘 .”29）说明咳，喘等症与肾有兊。肾主纳气是指肾有摄 纳肺气，促进其吸清呼浊，防止呼吸表浅的作用。由于 肾中所藏的精气, 既是机体生命活动的原动力, 也是 气化作用的原动力, 全身的津液要通过肾的气化作 用，升清降浊，使体内有用的津液蒸腾上升，向各脏 腑布散多余的津液化为尿液, 注入膀胱排出.

综上大致可以看出『黄帝内经』认为肾的生理功能主 要有三个方面: 一主藏精, 主生长与生殖, 二主水液, 三主纳气。

\section{III.结 语}

肾气丸是中医异病同治的典型方例，体现出中医辨 证论治的治疗思想. 从上可以看出，张仲景在『金苪要 略』中运用肾气丸时, 是以恢复肾脏气化功能为目的. 治疗肾气虚而失气化, 导致水液代谢失调为病机的疾 病. 方中虽有温阳益精之品, 肾气丸之方义却不在填 补肾精或温补肾阳, 而是借肾阳蒸化肾阴, 以肾精化 生肾气, 纵观全方, 填精补肾的地黄8两, 温性之附子, 桂枝, 山莫肉共6两. 性寒之泽泻, 丹皮6两, 性本之山 药, 获苓7两, 全方药性平而不热, 故肾气丸非温补肾 阳之方剂, 功实在化气利水, 故方名肾气丸. 正如柯琴 所云: “肾气丸意不在补火, 而在微微生火, 即生肾气也, 故不曰温肾, 而名肾气”(『名医方论』) 张山雷的「小儿 药证直诀笺正」最为直接地指出: “仲师八味, 全为肾气 不充, 不能鼓舞真阳, 而小便不利者设法”, 故以桂附 温煦肾阳，地黄滋养阴液，莫肉收摄耗散，而既以丹 皮泄导湿热, 获苓、泽泻利膀脱, 其用山药者, 实脾 以堤水也. 立方大旨, 无一味不从利水着想。方名肾 气, 所重者一气字.

气化是激发和调控人体生命活动的动力源泉, 推动 和调节人体精微物质新陈代谢和能量转化, 调控脏腑 功能 凡物之成形者, 皆有气化活动存乎其中, 升降出

28）马莳 撰. 黄帝内经灵枢注证发微。北京. 人民卫生出版社. 1998. p.165.

29）马莳 撰. 黄帝内经灵枢注证发微。北京. 人民卫生出版社. 1998. p.232.
入是其基本表现形式. 升降出入正常与否，又与“枢”的 运转状况密切相爸。『素问』阴阳离合论」日：“太阳为 开……阴为开，劂阴为合，少阴为枢”。少阴司水 火, 内寓真阴真阳，为调节阴阳，水火升降出入平衡之 重要枢纽. 枢机系于此，故气化之根在于少阴气化．肾 属少阴，肾中寓真阴真阳，为气化之源. 肾气司化膀脱 开圈, 主水液代谢, 蒸化其中水液, 升清降浊. 气化布 于三焦全身各处，人体精微物质化生为各脏腑之精， 再由脏腑之精化为脏腑之气，推动和调节脏腑精微物 质的新陈代谢及能量转化, 肾受拄腑之精而藏之, 由 此气化循环无穷. 所以少阴气化得利, 则精微及时转 化，不会滞留血中而发为痰，浊，瘀。『素问』阴阳离 合论」说人体有枢机三个，也为气机出入的道路，即脾 胃升降之枢，少阳之枢，少阴之枢. 在三焦，枢机的协 调之下，气化路通，精微正化散布于全身各处，激发和 调控脏腑的功能活动和新陈代谢. 故少阴肾作为人体重 要的枢机所在, 其气化的正常与否与人体各脏腑的生 理功能, 精微物质的传化吸收, 㾋水饮痰的代谢密切 相兊, 故仲景重视少阴肾之气化, 立温阳化气之法, 创金實肾气之方，从温肾利水，恢复气化功能入手， 正所谓“大气一转, 其气乃散”, 肾脏气化功能正常, 则全身气血津液代谢尤其是水液代谢功能正常. 所以张 仲景对肾脏气化功能及其主水液代谢思想尤为重视, 然而仲景爸于肾脏气化的理论是根源于『黄帝内经』中 肾纳气，主生殖，发育等基本功能之上的，两者一脉相 承不能孤立, 割裂去认识.

\section{参考文献}

〈단행본>

1. 马莳 撰. 黄帝内经灵枢注证发微. 北京. 人民卫 生出版社. 1998. p.6, 8, 29, 87, 122, 165, 232, 376, 682.

2. 尤怡 著. 金惯翼. 北京. 中医古籍出版社. 2003. p.179.

3. 尤怡 著. 金贯. 要略心典. 上海. 上海卫生出版社. 1956. p.33, 57, 103, 194, 226. pp.70-71, 393-394.

4. 杨土瀛 著. 仁斋直指方论. 福建. 福建科学技术 出版社. 1989. p.276. 
5. 林佩琴 编著. 类证治裁. 上海. 上海科学技术出 版社. 1959. p.113.

6. 吴谦等 著. 医宗金鉴·杂病心法要诀白话解. 北 京. 人民卫生出版社. 2004. p.165.

〈학술지 논문>

1. 管华全, 樊巧玲, 张永文. 肾气丸与右归丸主治疾 病比较. 浙江中医药大学学报, 2010. 34(1). pp.81-82.

2. 晋玉梅. 金贾肾气丸治疗咳嗽的体会. 河南中医 药学刊. 1997. 12(4). pp.39-40.

3. 李安祥. 金贵肾气丸的五点思考. 中医药通报. 2011. 10(1). pp.7-9. 